\title{
Gabriel Corcuera
}

En 195I, se publica uno de los libros más significativos y representativos del pensamiento de Theodor W. Adorno. Con un particular estilo y uso del lenguaje aforístico y fragmentario, con el cual se critica la interpretación histórico-filosófica de la realidad social que identifica a esta como un objeto estático, Minima moralia se presenta como un diagnóstico del alto grado de enajenación alcanzado por el individuo y la sociedad a la que pertenece. La sociedad, lejos de estar sujeta a una conceptualización que la reduce a un objeto fijo y estable de estudio, es presentada en su diversidad microscópica y contradictoria que se evidencia en las circunstancias de la vida en sus más pequeños y mínimos detalles.

Los aforismos de Minima moralia fueron escritos por Adorno entre los años 1944 y 1947. Las tres partes en las que se divide el libro corresponden a los tres momentos en que respectivamente las escribió. El primer conjunto de aforismos fue escrito en 1944; el segundo, en 1945; y el último conjunto, entre 1946 y 1947.

En febrero de 1945, Adorno, con motivo del cumpleaños número cincuenta de Max Horkheimer, le entregó, como un gesto de aprecio, “(...) un texto dedicado a él que estaba lleno de 'elementos propios': Minima Moralia, con la inscripción manuscrita: 'Cincuenta aforismos con motivo del cumpleaños número 50 de Max Horkheimer, Los Ángeles-Nueva York, 14 de febrero de 1945'. Más tarde, éstos constituyeron la primera parte de Minima Moralia. 
Reflexionen aus dem beschädigten Leben [Minima moralia. Reflexiones desde la vida dañada], cuya segunda parte la recibió Horkheimer en la Navidad de 1945, con la dedicatoria 'Para Max. Por el retorno', y cuya tercera parte fue redactada en los años de 1946 y 1947"'. Por "elementos propios" se entiende la consideración de que si bien las reflexiones son de la pluma del propio Adorno con relación a Horkheimer y debido a que en aquellos tiempos, por circunstancias externas, tuvieron que interrumpir el trabajo en común, aquel señala en la Dedicatoria que: "Este libro quiere ser manifestación de gratitud y lealtad, pero sin aceptar la interrupción. Él es un testimonio de una dialogue intérieur: ningún motivo se encuentra en él que a Horkheimer no le hubiera incumbido tanto como al que halló tiempo para formularlo" 2 .

Esta deferencia de Adorno con Max Horkheimer permite comprender la elaboración de Minima moralia como la "continuación aforística de la Dialéctica de la llustración, o la continuación de la parte de aforismos de la misma"3.

\section{§ 1. Crítica al hegelianismo, lenguaje fragmentario y los más mínimos detalles}

En este sentido, la continuación no sólo implica las consideraciones teóricas, sino también el estilo o el lenguaje para manifestarlas. Los textos de Adorno son "composiciones textuales concentradas, a las que subyace la idea de que los pensamientos tienen justamente el mismo valor que la forma lingüística en la que se exteriorizan"4. Como una ramificación de los aforismos contenidos en la última parte de Dialéctica de la llustración, en Minima moralia Adorno los sigue empleando como una salida o una forma de expresar o buscar un modo de plasmar fielmente sus reflexiones de alcance crítico-social. Estos aforismos tienen la particularidad de no serlo en un sentido tradicional, sino de situarse entre el "aforismo extenso" y el "ensayo corto", del modo como

' Wiggershaus, Rolf, La Escuela de Frankfurt, Buenos Aires: FCE, 2010, p. 466.

2 Adorno, Theodor, Minima moralia. Reflexiones desde la vida dañada, traducción de David Mielke, Madrid: Taurus, 200I, p. 9.

3 Wiggershaus, Rolf, op. cit., p. 494.

4 Wellmer, Albrecht, Sobre la dialéctica de modernidad y postmodernidad. La crítica de la razón después de Adorno, Madrid: Visor, 1993, p. 135. 
a ellos se refiriera Thomas Mann ${ }^{5}$. Es decir, no se trata de aforismos a modo de breves sentencias, sino de aforismos cuyo contenido se desarrolla y se hace explícito, pero no con la intención de mostrar una reflexión terminada o establecida, sino afirmando, con su corta extensión y su fragmentariedad, un pensamiento crítico-inmanente y no una aspiración a una totalización que traicione la continuidad de una crítica.

En su discurso de aceptación de la Cátedra de Filosofía de la Universidad de Frankfurt de 1930, Adorno, con 27 años, empezaba diciendo: "Quien hoy elija por oficio el trabajo filosófico, ha de renunciar desde el comienzo mismo a la ilusión con que antes arrancaban los proyectos filosóficos: la de que sería posible aferrar la totalidad de lo real por la fuerza del pensamiento"6. Todo sistema filosófico, valga decir "cerrado", se tropieza con el engaño de la posibilidad de llegar a establecer una identificación entre concepto y objeto. Adorno critica, en este sentido, una filosofía de la historia que llegue a su culminación y que, a partir de ello, desvirtúe y reduzca todo proceso histórico, social y humano a la conformación de tal sistema. Todo proceso, pues, no es sino un momento entre otros que en su negación dialéctica es una mera fase o figura del télos alcanzado. Es la crítica a la interpretación totalitaria de la realidad la que, en los tiempos de Adorno, asumiendo la pretensión del pensamiento en tanto totalizador, ha devenido en dominación y absolutismo, alienación de las relaciones sociales y barbarie, expansión de las relaciones de producción e instrumentalización del sujeto, pérdida de la experiencia y degeneración de la libertad del individuo y, finalmente, desintegración del individuo mismo y la humanidad.

La crítica a la dialéctica hegeliana en tanto "aspiración a un sistema”, es decir, en tanto búsqueda de la identificación como vehículo interpretativo de la realidad, es a la que se refiere Adorno en la Dedicatoria de Minima moralia, en donde dice que, contrariamente al proceder de Hegel pero, sin embargo, de un modo acorde con su pensamiento, sus aforismos insisten en la negatividad, y cita el siguiente fragmento de la Fenomenología del espíritu: "La vida del espíritu sólo conquista su verdad cuando se encuentra a sí mismo en el

5 Cf. Claussen, Detlev, Theodor W. Adorno: One Last Genius, Londres: Harvard University Press, 2008, pp. 142-143.

6 Adorno, Theodor, Actualidad de la filosofía, Barcelona: Paidós, 1994, p. 73. 
absoluto desgarramiento. El espíritu no es esta potencia como lo positivo que se aparta de lo negativo, como cuando decimos de algo que no es nada o que es falso $y$, hecho esto, pasamos sin más a otra cosa, sino que sólo es esta potencia cuando mira cara a cara a lo negativo y permanece cerca de ello"7. Se trata, entonces, de entender la realidad como aquello que la negatividad de la transición dialéctica hegeliana pretende superar. No es la realidad la superación de sus momentos, sino sus momentos mismos. Así, estos momentos son la fragmentariedad de la sociedad, son las partículas que la constituyen y que, lejos de ser susceptibles de una superación, se comportan bajo una dinámica de cambio continuo, de una sucesión no teleológica. El método dialéctico, para Adorno, no tiene que servirse de la negatividad para afirmar la identidad entre concepto y objeto, que viene a ser finalmente el espíritu absoluto en Hegel, sino que la dialéctica tiene que servirse de la negatividad para afirmar más bien la no identidad de pensamiento y realidad o, dicho en otras palabras, para evitar la sistematización de la sociedad y sus procesos históricos. Esta es la empresa que recorre todo el pensamiento de Adorno y que tiene en Dialéctica negativa ${ }^{8}$, obra de 1966, su presentación más "sistemática".

Por otro lado, el estilo aforístico usado por Adorno, en tanto aproximación al carácter fragmentario de la realidad, se perfila desde las influencias que inciden en su pensamiento. Así,s por ejemplo, uno de los rasgos más prominentes del materialismo de Adorno tiene como génesis la influencia de Walter Benjamin. Éste, con su escrito de los años $20 \mathrm{El}$ origen del drama barroco alemán, prefigura la idea de Adorno de que la "especificidad material de los pequeños detalles revelados por la investigación histórica y filológica más que los más generales y abstractos $y$, por lo tanto, vacíos conceptos, debiera ser el punto de inicio para la interpretación filosófica"9. Y es que para Adorno el concepto no agota lo concebido, siempre hay algo que no aprehende, que se le escapa. La realidad no puede reducirse a los conceptos si con estos se pretende una referencia a la totalidad de lo real. Más bien, se ha de buscar la manera de pensar la realidad y de referirse a ella de manera tal que pueda expresarse su originalidad dinámica, múltiple y particularizada.

7 Adorno, Theodor, Minima moralia, p. II.

8 Adorno, Theodor, Dialéctica negativa, Madrid: Taurus, 1975.

9 Huhn, Tom, The Cambridge Companion to Adorno, Cambridge: Cambridge University Press, 2006, p. 84. 
Se trata, entonces, de pensar la particularidad más que la generalidad. "La 'mirada microscópica' de Benjamin, como la llamara Adorno, a través de la cual se destacaban los objetos más triviales, era una característica personal, pero era también algo más. Como herramienta para el conocimiento filosófico, era un medio para que cada mínima particularidad del objeto liberara una significación que disolvía su apariencia reificada y la revelaba como algo más que simplemente idéntica a sí misma. Al mismo tiempo, el conocimiento liberado permanecía adherido a lo particular en lugar de sacrificar su especificidad material en un nivel de abstracta generalización ahistórica"10. Son estos "pequeños detalles”, estos "objetos triviales", los que, para Adorno, toda reflexión filosófica debiera alcanzar y a los que se puede llegar con una crítica de la sociedad. Es a llegar a estos detalles a lo que aspiran, por tanto, las reflexiones de Minima moralia en tanto contenido y estilo. La "mirada microscópica" tiene que enfrentarse a la vida alienada o, como dice Adorno en la Dedicatoria, "Quien quiera conocer la verdad sobre la vida inmediata tendrá que estudiar su forma alienada, los poderes objetivos que determinan la existencia individual hasta en sus zonas más ocultas"'!.

Pero, isobre qué tiene que versar esta verdad? "La ciencia melancólica de la que ofrezco a mi amigo algunos fragmentos, se refiere a un ámbito que desde tiempos inmemoriales se consideró el propio de la filosofía, pero que desde la transformación de ésta en método cayó en la irreverencia intelectual, en la arbitrariedad sentenciosa y, al final, en el olvido: la doctrina de la vida recta"'2. Una vida recta, de cuya posibilidad en Minima moralia Adorno reflexiona consciente de lo complejo que resulta una afirmación esperanzadora si se toma en cuenta la seriedad crítica de los momentos de la época. Es decir, si es posible -a la sombra de la Segunda Guerra Mundial, de Auschwitz, de genocidios, del dominio como instrumentalización e industrialización, de la masificación de los individuos y su caída en la esfera del consumo, del control y domino político-económico y pérdida de la libertad, del falso concepto de autenticidad, de la pérdida progresiva de la experiencia de la historia-concebir

${ }^{10}$ Buck-Morss, Susan, El origen de la dialéctica negativa, Buenos Aires: Siglo XXI Editores, 198I, p. 162.

"Adorno, Theodor, Minima moralia, p. 9.

12 lbid. 
una vida justa que sea plausible. "No cabe la vida falsa en la vida justa"13. Es esta vida falsa la forma alienada de la vida inmediata que debe conocer quien quiera comprender la verdad de la misma. Es así como se presenta la vida en su inmediatez y es la exigencia de Adorno encontrar en ella hasta en los más mínimos aspectos la forma alienada como objeto de crítica social.

Aquella "ciencia melancólica" a la que Adorno hace referencia es una reivindicación de la "ciencia jovial" nietzscheana, ya que Adorno comparte la concepción de una "transvaloración de todos los valores": "Adorno comparte la intención de la epistemología nietzscheana de demostrar que la aparente estabilidad del mundo o los valores surgen de un sistemático menosprecio de los aspectos dinámicos de la realidad en nuestro pensamiento y nuestra filosofía"'4.

A partir de un retrato fragmentario de la sociedad se hace posible desprenderse de la ilusión de una sociedad compacta y estable; se logra desvelar cómo la aspiración totalitaria invade cada aspecto de la vida, aspectos en que la identificación entre concepto y sociedad pierden su efecto mágico de dominación y puede abrirse paso una crítica de la sociedad, ya que los conceptos en su uso ordinario distorsionan y enmascaran la realidad social ${ }^{15}$. Es por eso que los textos de Adorno presentan un lenguaje y estilo que buscan reflejar una teoría crítica no sistematizada para no traicionar la crítica misma de la sociedad.

\section{§ 2. Una experiencia de catástrofe mundial}

El tema de Auschwitz y la Segunda Guerra Mundial tiene un lugar relevante en el pensamiento y la reflexión crítica de Adorno. En Minima moralia, aparece con especial énfasis en algunos de los aforismos. Auschwitz y la Segunda Guerra Mundial son identificados como una incomprensible catástrofe mundial del proceso "civilizatorio" de occidente que devino en barbarie, marcando un punto de quiebre generacional después del cual se hace imposible volver a concebir la vida con alguna luz de esperanza. Ante lo sucedido, no se puede más que

\footnotetext{
13 Ibid., p. 192.

${ }_{14}$ Rose, Guillian, Melancholy Science: An Introduction to the Thought of Theodor Adorno, Nueva York: Columbia University Press, 1978, p. 19.
}

$146{ }^{15}$ Cf., ibid., p. II. 
partir de la concepción de una vida dañada y buscar en la historia de occidente aquello que no fue contando en cada momento y que luego se manifestó en la forma de la más terrible avalancha: "Minima moralia de Adorno es un texto que implica una lectura repetida y que, como el más famoso libro de Horkheimer y Adorno, Dialéctica de la llustración, encapsula la experiencia en un momento de la historia que pone en cuestión toda experiencia tradicional del mundo. (...) Cada sentencia en aquellos libros adquiere su fuerza argumentativa de la consciencia de ambos autores de una catástrofe histórico-mundial que no dejará nada inalterado"16.

De esta manera, en la sección aforística de Dialéctica de la llustración -texto cuya redacción culminó en el año de 1944-, ambos autores conciben irremediablemente, con relación a la situación de la guerra, en el aforismo "Alud", que "en la actualidad no hay ya más cambios. Cambio es siempre cambio hacia lo mejor. Pero cuando, en tiempos como los actuales, la angustia ha llegado al culmen, el cielo se abre y vomita su fuego sobre los ya perdidos. Cuando el número de votos de Hitler empezó a subir, primero de forma débil pero regular era ya evidente que el alud se había puesto en movimiento"17.

En Minima moralia, el tono de las reflexiones no podría no seguir, pues, el mismo color gris y pesimista debido a la perturbación generada por la catástrofe desencadenada. No se puede seguir viviendo después de Auschwitz: "Pensar que después de esta guerra la vida podrá continuar enormemente y aun que la cultura podrá ser 'restaurada' -como si la restauración de la cultura no fuera ya su negación-, es idiota. Millones de judíos han sido exterminados, y esto es sólo un interludio, no la verdadera catástrofe"18. El aforismo citado, “Lejos del fuego", que pertenece a la primer parte (1944) de Minima moralia, muestra incluso cómo con el término de la guerra no se daría lugar a ningún tipo de restauración, y es que, evidentemente, lo inhumano ya se ha expresado y toda manifestación de la misma es ya la ruptura de cualquier esperanza concreta de reconciliación.

16 Claussen, Detlev, op. cit., p. 6.

17 Adorno, Theodor y Max Horkheimer, Dialéctica de la llustración, Madrid: Trotta, 1998, p. 264.

${ }^{18}$ Adorno, Theodor, Minima moralia, p. 53. 
Pero esta manifestación de inhumanidad tiene detrás de ella la historia. Para que ella haya tenido que llegar hasta los extremos de la guerra, tiene que haberse ido configurando en cada momento de la historia, en los cuales no fue advertido cada brote de barbarie que se fue produciendo y originando. La experiencia de los hombres ha ido progresivamente olvidando cada uno de esos sucesos y ha permanecido en un presente que olvidó lo que se fue dejando atrás: "Con cada explosión se destruyen, dondequiera que se hallen, los muros a cuyo amparo germina la experiencia y se asienta la continuidad entre el oportuno olvido y el oportuno recuerdo"'19.

Benjamin, con su énfasis en la pérdida de la experiencia, hacía referencia a la Primera Guerra Mundial como un acontecimiento que remeció la vida de los que la padecieron e impuso un punto de quiebre generacional. Adorno, por su parte, retoma la misma idea para hacer referencia a la Segunda Guerra Mundial, en la cual observa una mayor pérdida de la experiencia, producto de la tecnificación e industrialización de la guerra que termina mecanizando a esta: "Ya la vez pasada la inadecuación del enfrentamiento físico a la guerra técnica había hecho imposible la verdadera experiencia de la guerra. Nadie habrá podido relatar entonces lo que todavía se podía relatar de las batallas del general de artillería Bonaparte. (...) Pero a esta segunda guerra le es ya tan completamente heterogénea esa experiencia como al funcionamiento de una máquina los movimientos corporales, que sólo en ciertos estados patológicos se le asemejan. Cuanto menos continuidad, historia y elementos 'épicos' hay en una guerra, (...) menos es capaz de dejar una impresión duradera e inconsciente en el recuerdo" 20 .

A partir de este aforismo se puede observar el modo en que Adorno llega a percibir cómo la experiencia de la guerra ha dejado de ser una experiencia humana (de "continuidad, historia y elementos "épicos") y se ha tornado en una experiencia cuyos autores, ejecutantes y combatientes se han convertido en una maquinaria industrial con su respectiva dinámica económica de producción, de relaciones de mercado, de enajenación del individuo y su pérdida de capacidad de recordar lo padecido: "Quien se sustrae a la evidencia del

19 Ibid., p. 52.

20 lbid. 
crecimiento del espanto no sólo cae en la fría contemplación, sino que además se le escapa, junto con la diferencia específica de lo más reciente respecto a lo acaecido anteriormente, la verdadera identidad del todo, del terror $\sin$ fin" ${ }^{21}$. Lo que está detrás de todo esto es una concepción hegeliana de la historia en tanto concretización de un sistema filosófico que llega a su completitud y que ha servido como motor y posibilitador de todo sistema de dominio. El sujeto queda reducido a su identificación con la idea, con el sistema de pensamiento, sistema que ha recogido los momentos históricos estructurándolos bajo su forma, así como simultáneamente negando, superando y olvidando sus antítesis de destrucción y deshumanización: "Si la filosofía de la historia de Hegel hubiera podido incluir esta época, las bombas-robot de Hitler habrían encontrado su lugar, al lado de la muerte prematura de Alejandro y otros cuadros del mismo tipo, entre los hechos empíricos por él escogidos en los que se expresa simbólicamente el estado del espíritu del mundo”22.

El momento crítico de la Segunda Guerra Mundial y de Auschwitz -momento presente en la vida de Adorno- fue, pues, más acuciantemente, lo que lo llevó a reformular y reflexionar acerca del pasado y de la historia en el sentido de buscar una explicación a cómo fue posible llegar a tal grado de barbarie en la actualidad. No se puede obviar lo que sucede en el presente -más aun si se trata de un presente inhumano e irracional- ni pensar la actualidad de una manera seria, sin que esto no nos induzca a reinterpretar lo anteriormente sucedido. Si la actualidad es terrible e inhumana es deudora de una historia en la que se han de encontrar las condiciones que hacen posible tal episodio que, lejos de mostrarse bajo una idea de progreso, se presenta como un conjunto de momentos aciagos cuya acumulación y continuidad no se supo evitar ni detener. Por eso, quien ante la oscuridad del presente se suma en la desesperación, tiene que reconocer que "La desesperación no tiene la expresión de lo irrevocable porque la situación no pueda llegar a mejorar, sino porque arrastra a su abismo al tiempo pasado. Por eso es necio y sentimental querer mantener el pasado limpio de la sucia marea del presente. El pasado no tiene otra esperanza que la de, abandonado al infortunio, resurgir de él transformado. Pero quien muere desesperado es que su vida entera ha sido inútil" 23 .

\footnotetext{
${ }^{21}$ Ibid., p. 237.

22 Ibid., p. 53.

23 lbid., p. 167.
} 